\title{
A prospective analysis of polycystic ovarian syndrome in infertile women
}

\section{Soumya Patil*, Saraswathi Ramesh, Harinath Srinivasa Murthy Kharidhi}

Department of MIS Gynecology, BEST Institute and Research centre, AV Hospital, Basavanagudi, Bangalore, Karnataka, India

Received: 03 November 2018

Accepted: 06 December 2018

*Correspondence:

Dr. Soumya Patil,

E-mail: soumyarpati1999@gmail.com

Copyright: () the author(s), publisher and licensee Medip Academy. This is an open-access article distributed under the terms of the Creative Commons Attribution Non-Commercial License, which permits unrestricted non-commercial use, distribution, and reproduction in any medium, provided the original work is properly cited.

\section{ABSTRACT}

Background: Polycystic ovarian syndrome (PCOS) is a frequently occurring metabolic and reproductive endocrinopathy. Young women with PCOS mainly present with reproductive problems such as hyperandrogenism, menstrual irregularities, infertility and chronic anovulation. Despite its high prevalence and implications on reproductive health, PCOS is underdiagnosed. The objective was to study the prevalence of PCO in women with infertility, their symptomatology, endocrine profiles and coexisting factors of infertility in women with PCOS.

Methods: A prospective study was performed over a period of 6 months. Women presenting with infertility were subjected to detailed history taking, general and gynecological examination. Women with features of PCOS on ultrasound were identified and advised investigations such as serum FSH, LH, prolactin and laparoscopy when indicated.

Results: During the study period, 102 patients consulted the infertility clinic, out of which 56 were diagnosed with PCOS. The prevalence of PCOS was found to be $54.9 \%$ among infertile women. Menstrual irregularity was found in $33(59 \%)$ women, however, $23(41 \%)$ had regular menstrual cycles. 4 among the 33 patients complained of dysmenorrhea, 5 had heavy menstrual bleeding. On examination, 19 (33.9\%) were found hirsute, $8(14.28 \%)$ had thyroid enlargement and $2(3.57 \%)$ had galactorrhea. Investigations revealed mean FSH and LH levels of $8.7 \pm 2$ SD and 13.7 \pm 2 SD respectively and mean $\mathrm{LH} / \mathrm{FSH}$ ratio of $1.57 \pm 2 \mathrm{SD}$.

Conclusions: PCOS is a heterogenous disorder and with its high prevalence in infertile women, proper diagnosis and management is essential as it has many potential metabolic and cardiovascular risks if not managed appropriately.

Keywords: Hyperandrogenism, Hirsutism, Infertility, Laparoscopy in PCOS, PCOS, Serum Values of FSH and LH in PCOS, Symptoms of PCOS

\section{INTRODUCTION}

Polycystic ovarian syndrome (PCOS), also known as Stein-Leventhal syndrome, is a frequently occurring metabolic and reproductive endocrinopathy. Prevalence in reproductive age group is reported in various studies as $5-20 \% .^{1-3}$ PCOS women present with a constellation of symptoms which significantly impacts the quality of life. These women are at higher risk for various morbidities such as obesity, insulin resistance, type II diabetes mellitus, cardiovascular disease (CVD), infertility, malignancy, and psychological disorders. ${ }^{3}$ Young women with PCOS mainly present with reproductive problems such as hyperandrogenism, menstrual irregularities, infertility and chronic anovulation. Infertility increases 10 folds in women with PCOS and affects up to $40 \% .^{2-4}$ PCOS reduces fertility due to associated endocrine, metabolic and gynecological abnormalities that impact on 
the quality and function of the ovary. Derangements in factors involved in normal follicular development lead to arrest of follicular growth as the follicles reach a diameter of 4-8 $\mathrm{mm}$, dominant follicle does not develop, and ovulation does not ensue. Increased insulin resistance which causes an increased LH/FSH ratio and decreased SHBG leads to hyperandrogenism. Studies have also reported poor pregnancy outcomes in these women. ${ }^{5,6}$

There is no single definitive test to diagnose PCOS, however, three different guidelines, National institute of health criteria (NIH), Androgen excess- PCOS society of India criteria (AE-PCOS) or Rotterdam criteria can be followed. ${ }^{7-9}$ Insulin resistance and obesity are considered intrinsic to PCOS but neither of them is included in the guidelines and should therefore be used for diagnostic purposes. ${ }^{10}$ Despite its high prevalence and implications on reproductive health, PCOS is underdiagnosed. The objectives of the present survey were to study the prevalence of PCO in women with infertility, their symptomatology, endocrine profiles and coexisting factors of infertility in women with PCOS.

\section{METHODS}

A prospective study was performed at BEST Institute and Research Centre, AV hospital, Bangalore over a period of 6 months. Women presenting with infertility were subjected to detailed history taking, general and gynecological examination. History was obtained for such as age, occupation, married life, type of infertility, parity index, menstrual history, obstetric history, sexual history and past medical or surgical illness. A comprehensive general examination was performed to note height, weight, BMI, thyroid enlargement, galactorrhea and hirsutism. Speculum, bimanual examination and ultrasound examination was carried out. Women with features of PCOS on ultrasound were identified and advised investigations such as serum FSH, LH (on day $2 / 3$ of cycle), prolactin, $\mathrm{AMH}$ and laparoscopy when necessary.

PCOS was defined by Rotterdam criteria (includes any 2), Clinical and/or biochemical hyperandrogenism, oligoovulation or anovulation, polycystic ovaries. The diagnosis of Polycystic ovaries was made on USG if there were presence of 12 or more peripheral follicles each 2-9 $\mathrm{mm}$ in diameter in one or both ovaries, increased ovarian volume $\left(10 \mathrm{~cm}^{3}\right)$ in one or both ovaries.

Data were collected in a preformed data collection sheet. Collected data was compiled and tabulated in a Microsoft excel sheet and analyzed. Appropriate statistical parameters were used to analyze the patient distribution based on various parameters.

\section{RESULTS}

During the study period, 102 patients consulted the infertility clinic, out of which 56 were diagnosed with
PCOS. The prevalence of PCOS was found to be $54.9 \%$ among infertile women.

Among the 56 patients diagnosed with PCOS, 48 $(85.71 \%)$ of them were in $21-30$ years of age group, 7 $(12.5 \%)$ of them were $>30$ years and $1(1.78 \%)$ below 20years of age. The mean age of these women was $26.23 \pm 2 \mathrm{SD}$ as depicted in Table 1 .

Table 1: Age distribution, BMI, menstrual cycle, type of infertility and hirsutism among study subjects.

\begin{tabular}{|c|c|c|c|}
\hline Variable & Distribution & Number & Percentage \\
\hline \multirow{3}{*}{ Age } & $<20$ years & 1 & 1.78 \\
\hline & $21-30$ years & 48 & 85.71 \\
\hline & $31-35$ years & 07 & 12.5 \\
\hline \multirow{5}{*}{ BMI } & $<18 \mathrm{~kg} / \mathrm{m}^{2}$ & 02 & 3.5 \\
\hline & $18-25 \mathrm{~kg} / \mathrm{m}^{2}$ & 25 & 44.64 \\
\hline & $26-30 \mathrm{~kg} / \mathrm{m}^{2}$ & 16 & 28.57 \\
\hline & $31-35 \mathrm{~kg} / \mathrm{m}^{2}$ & 11 & 19.6 \\
\hline & $>35 \mathrm{~kg} / \mathrm{m}^{2}$ & 02 & 3.5 \\
\hline \multirow{2}{*}{$\begin{array}{l}\text { Menstrual } \\
\text { irregularity }\end{array}$} & Regular & 23 & 41 \\
\hline & Irregular & 33 & 59 \\
\hline \multirow{2}{*}{$\begin{array}{l}\text { Type of } \\
\text { infertility }\end{array}$} & Primary & 40 & 71.42 \\
\hline & Secondary & 16 & 28.57 \\
\hline \multirow{2}{*}{ Hirsutism } & Present & 19 & 33.9 \\
\hline & Absent & 37 & 66.1 \\
\hline
\end{tabular}

Majority of these women had married life of 1-5 years $(67.8 \%)$. Mean BMI among them was 27.24 \pm 2 SD. Menstrual irregularity was found in $33(59 \%)$ women, however, $23(41 \%)$ had regular menstrual cycles. 4 among the 33 patients complained of dysmenorrhoea, 5 had heavy menstrual bleeding and 1 patient reported of having bleeding only after withdrawal was given. 40 $(71.42 \%)$ were nulliparous and presented with primary infertility and $16(28.57 \%)$ of them presented with secondary infertility, out of which 2 had previous ectopic pregnancies, 12 had previous miscarriages and 2 patients had preterm deliveries without a living issue.

Previous medical illness was reported in 15 (26.79\%) patients. 3 of them had diabetes mellitus and were on treatment and 1 among them underwent gastric bypass surgery for the same. Hypothyroidism (10 patients), hyperprolactinemia (1) and asthma (1) were other medical illnesses noted. On examination, 19 (33.9\%) were found hirsute, $8(14.28 \%)$ had thyroid enlargement and $2(3.57 \%)$ had galactorrhoea. 5 women had evidence of PID and 1 had septate vagina on gynecological examination. Investigations as depicted in Table 2 revealed mean FSH and $\mathrm{LH}$ levels of $8.7 \pm 2 \mathrm{SD}$ and $13.7 \pm 2 \mathrm{SD}$ respectively and mean $\mathrm{LH} / \mathrm{FSH}$ ratio of $1.57 \pm 2 \mathrm{SD}$.

Among 56 women, $44(78.57 \%)$ were euthyroid, 4 (7.14\%) had sub-clinical hypothyroidism and 1 had overt hypothyroidism. Serum prolactin was raised $(>25 \mathrm{ng} / \mathrm{mL})$ in $4(7.14 \%)$ women. 
Table 2: Investigations of the study subjects.

\begin{tabular}{|l|l|l|}
\hline \multirow{5}{*}{ Variable } & Distribution & Number \\
\hline \multirow{3}{*}{ LH/FSH ratio } & $<1$ & 25 \\
\cline { 2 - 3 } & $1-2$ & 18 \\
\hline TSH - Euthyroid & $2.1-2.9$ & 10 \\
\hline Sub clinical & $\geq 3$ & 03 \\
\hline Overt & $0.39-4.6 \mathrm{mI} \mathrm{U} / \mathrm{L}$ & 44 \\
\hline PRL & $4.6-20 \mathrm{mI} \mathrm{U} / \mathrm{L}$ & 04 \\
\hline \multirow{2}{*}{ USG } & $>20 \mathrm{mI} \mathrm{U} / \mathrm{L}$ & 01 \\
\hline & $>25 \mathrm{ng} / \mathrm{mL}$ & 04 \\
\hline & PCOS & 47 \\
\hline & Normal & 04 \\
\hline
\end{tabular}

On ultrasound examination, $50(89.3 \%)$ women had features of PCOS. Diagnostic laparoscopy was carried in these women when indicated and 47 of them showed features of PCOS in one or both ovaries and 1 had normal findings on laparoscopy. In 6 patients' laparoscopy was not found necessary and hence not performed.

Co-existing factors of infertility with PCOS that were noted in the present study were, 9 had endometriosis along with PCOS, 4 had coexistent tubal factor and hyperprolactinemia each.

\section{DISCUSSION}

PCOS is a set of symptoms owing to underlying endocrinopathy. Infertility due to PCOS is one of the concerning consequences which is subjected to continuous studies. Not all women with PCOS are infertile. For those that do, anovulation, infrequent ovulation, altered levels of gonadotrophins, hyperandrogenemia and hyperinsulinemia are the causes cited. In India, experts claim rising trend of the women to be affected by PCOS and yet no proper published statistical data on the prevalence of PCOS in infertile women India is available. The prevalence depends on the diagnostic criteria used. In the present study, prevalence of PCOS in infertile women was up to $54.9 \%$. Worldwide, studies reported prevalence of PCOS in infertility as $53.4 \%, 40 \%$ and $56 \% .^{11-13}$

PCOS is closely associated with obesity, overweight and elevated BMI. Obesity is known to increase insulin resistance, hyperandrogenism and menstrual irregularities leading to further exacerbations of metabolic, reproductive and physiological features of PCOS. Mean BMI among the study patients was 27.24 2 SD which indicates that majority of women were overweight (25$\left.29 \mathrm{~kg} / \mathrm{m}^{2}\right)$ and obese $\left(>30 \mathrm{~kg} / \mathrm{m}^{2}\right)$. Similar findings were noted in various other studies. ${ }^{11,14,15}$ It has been suggested that even a modest loss of up to $5 \%$ of the initial body weight can result in spontaneous ovulation, restoration of menstrual cycle regularity, and pregnancy in obese women with PCOS. ${ }^{16}$ Menstrual irregularity is one of the key symptom of PCOS women and in present study, it was found in $59 \%$ women which correlates with other studies. ${ }^{17,18}$ Hirsutism was noted in $33.9 \%$ of women which was consistent with the findings published in literature of a few studies as $28 \%$ and $30 \% .^{18,19}$ However, few studies have reported a higher incidence $(64 \%)$ of hirsutism in women with PCOS. ${ }^{17}$ Derangement in the gonadotrophin ratio (FSH/LH) occurs in PCOS due to discriminate increase in LH levels. In the present study, deranged gonadotrophin ratio was noted in $54 \%$ of obese and overweight group. On ultrasound examination, $89.3 \%$ women were confirmed to have features of PCOS. Out of 56 women, 50 underwent laparoscopy for various reasons and 47 showed thickened, smooth and pearlwhite outer surface of the ovary which were labeled as PCOS. However, laparoscopy was not used as a diagnostic purpose in these women.

PCOS not only causes infertility but, if conceived also makes the women unable to maintain pregnancy. $25 \%$ of women in this study had history of at least single miscarriage. Hence, there is a need for intensified efforts in early detection, periodic monitoring and effective treatment in these high-risk women.

\section{CONCLUSION}

PCOS is a heterogenous disorder. There is a wide range in age of manifestation and symptomatology. Recent trends of sedentary lifestyle, carbohydrate and fat rich foods predispose adolescent girls to weight gain and high BMI. As a consequence, to these lifestyle changes there is an increased risk of PCOS, including hormonal imbalance, menstrual problems, infertility and altered pregnancy outcome in these women. PCOS has high prevalence in infertile women. Apart from its impact on reproductive outcome, PCOS also presents with delayed manifestations which has many potential metabolic and cardiovascular risks if not managed appropriately. Lifestyle modification at early age, counselling of the parents, better knowledge and attitude of women towards PCOS is crucial in improving the quality of life in women with PCOS.

\section{Funding: No funding sources \\ Conflict of interest: None declared}

Ethical approval: The study was approved by the Institutional Ethics Committee

\section{REFERENCES}

1. Melo AS, Ferriani RA, Navarro PA. Treatment of infertility in women with polycystic ovary syndrome: approach to clinical practice. Clinic. 2015;70(11):765-9.

2. Sirmans SM, Pate KA. Epidemiology, diagnosis, and management of polycystic ovary syndrome. Clinic Epidemiol. 2014;6:1.

3. El Hayek S, Bitar L, Hamdar LH, Mirza FG, Daoud G. Poly cystic ovarian syndrome: an updated overview. Front Physiol. 2016;7:124. 
4. Hart R, Doherty DA. The potential implications of a PCOS diagnosis on a woman's long-term health using data linkage. J Clinic Endocrinol Metabol. 2015;100(3):911-9.

5. Bruyneel A, Catteau-Jonard S, Decanter C, Clouqueur E, Tomaszewski C, Subtil D, et al. Polycystic ovary syndrome: what are the obstetrical risks?. Gynecol Obstet Fertil. 2014;42(2):104-11.

6. Kamangar F, Okhovat JP, Schmidt T, Beshay A, Pasch L, Cedars MI, et al. Polycystic ovary syndrome: special diagnostic and therapeutic considerations for children. Pediatr Dermatol. 2015;32(5):571-8.

7. Zawadski JK, Dunaif A. Diagnostic criteria for polycystic ovary syndrome: towards 417 a rational approach. Polycyst. 1992;418:377-84.

8. Azziz R, Carmina E, Dewailly D, DiamantiKandarakis E, Escobar-Morreale HF, et al. The Androgen Excess and PCOS Society criteria for the polycystic ovary syndrome: the complete task force report. Fertil Steril. 2009;91(2):456-88.

9. Fr DD, Tarlatzis R. Revised 2003 consensus on diagnostic criteria and long-term health risks related to polycystic ovary syndrome. Fertil Steril. 2004;81(1).

10. Witchel SF, Oberfield S, Rosenfield RL, Codner E, Bonny A, Ibáñez L, et al. The diagnosis of polycystic ovary syndrome during adolescence. Hormone Res Paediatr. 2015;83(6):376-89.

11. Ramani BV, Subbaiah MV, Devi VR, Umira SA, Keerthi KV, Priya SH. Fertility problems in women with polycystic ovary syndrome. Int $\mathrm{J}$ Reprod Contracept Obstet Gynecol. 2017;4(3):560-5.

12. Sirmans SM, Pate KA. Epidemiology, diagnosis, and management of polycystic ovary syndrome. Clinic Epidemiol. 2014;6:1.
13. Panchuk K, Lynam MJ. Polycystic Ovary Syndrome: Appreciating the Complexities and Implications of Diagnosis for Primary Care. UBC Med J. 2012;4(1).

14. Jalilian N, Haghnazari L, Rasolinia S. Leptin and body mass index in polycystic ovary syndrome. Ind $\mathbf{J}$ Endocrinol Metabol. 2016;20(3):324.

15. Gupta M, Singh D, Toppo M, Priya A, Sethia S, Gupta P. A cross sectional study of polycystic ovarian syndrome among young women in Bhopal, Central India. Int J Comm Med Public Health. 2017;5(1):95-100.

16. Butterworth J, Deguara J, Borg CM. Bariatric surgery, polycystic ovary syndrome, and infertility. J Obes. 2016;2016.

17. Choudhary A, Jain S, Chaudhari P. Prevalence and symptomatology of polycystic ovarian syndrome in Indian women: is there a rising incidence?. Int $\mathbf{J}$ Reprod, Contracept, Obstet Gynecol. 2017;6(11):4971-5.

18. Geetha K, Bijoy E, Hisham M. A Cross Sectional Study on Polycystic Ovary Syndrome in South Indian Population. Editorial 133 Research Articles. 2013:140

19. Khanam K, Parvin M. An Observational Study on 100 Patients with Polycystic Ovarian Syndrome (PCOS). J Enam Med College. 2014;4(3):156-60.

Cite this article as: Patil S, Ramesh $\mathrm{S}$, Kharidhi HSM. A prospective analysis of polycystic ovarian syndrome in infertile women. Int J Reprod Contracept Obstet Gynecol 2019;8:299-302. 